\title{
¿Qué significa apreciar la "naturaleza" como naturaleza?
}

\section{(What does Appreciating "Nature" as Nature Mean?)}

\author{
Sixto J. CASTRO
}

Recibido: 21 de mayo de 2014

Aceptado: 27 de abril de 2015

\section{Resumen}

En este artículo analizo la aproximación "estética" de Malcolm Budd a la naturaleza, que sostiene que el modo correcto de experimentar la naturaleza es "como naturaleza" y no como arte. Estudio su relación con la idea kantiana de belleza libre y trato de mostrar que la belleza libre es un recurso teórico que deriva de la inevitable belleza dependiente. Asimismo, basándome en la filosofía de Joseph Margolis, pretendo mostrar que "la naturaleza como naturaleza" es también un artefacto cultural.

Palabras clave: Budd, naturaleza, estética, Margolis.

\begin{abstract}
In this paper I analyze Malcolm Budd's "aesthetic" approach to nature that claims that the right way to appreciate nature is "as being nature" and not as being art. I study his dependence on Kant's free beauty and I try to show that free beauty is a theoretical device derived from the unavoidable dependent beauty. Besides, following Joseph Margolis" philosophy, I intend to show that "nature as nature" is also a cultural artifact.
\end{abstract}

Keywords: Budd, nature, aesthetics, Margolis. 


\section{Arte y naturaleza}

Según Susan Sontag, buena parte del arte moderno -que trata de volverse inaceptable para su público- en realidad expresa el hecho de que la presencia del público es inaceptable para el artista. El público, en este caso, se entiende como un conjunto de espectadores mirones, presentes pero ignorados por el artista o, en su caso, el actor, que refleja una concepción completamente ajena al mundo griego, al menos tal como lo considera Nietzsche en El nacimiento de la tragedia. Sontag subraya esta idea al afirmar que "gran parte del arte contemporáneo aspira a alcanzar (...) esta plenitud ideal a la que el público no puede añadir nada, análoga a la relación estética con la 'naturaleza'"1. De este modo, y a causa de la relación específica que establecemos con la naturaleza, aspiraríamos a que el arte se convirtiese en una suerte de "segunda naturaleza"2, y a que la relación que establecemos con el arte fuese semejante a la que establecemos con una naturaleza a la que dejamos que sea naturaleza, sin convertirla en una cosa ${ }^{3}$.

La aproximación "estética" de Malcolm Budd' a la naturaleza -que nos invita a abstraer de toda acción humana que pueda haber afectado a la naturaleza- podría interpretarse en esta línea (aunque él no siga la aplicación que Sontag hace de la relación con la naturaleza a la apreciación del arte). Budd niega que la naturaleza haya de ser apreciada como si fuese arte. Se debe apreciar: "(i) todo lo disponible en la naturaleza para la apreciación estética (como naturaleza), (ii) de cualquier manera o maneras en que sea posible apreciarla estéticamente (como naturaleza)"4, es decir, con una libertad y una relatividad de la que carecen los juicios estéticos relativos a la belleza del arte 5 . Budd insiste constantemente, a lo largo de toda su obra, en que el modo correcto de experimentar la naturaleza es "como siendo naturaleza" y nada más. "Una respuesta estética a algo natural -dice- constituye una apreciación estética de la naturaleza solo si la respuesta es una respuesta a la naturaleza en cuanto naturaleza" 6 , y la razón que aduce para ello es que "no toda experiencia estética disponible para un objeto natural es una instancia de la apreciación estética de la naturaleza"7. De ahí que la apreciación estética de la naturaleza tal

\footnotetext{
1 Sontag (2007), §10.

2 Margolis (2004); Margolis (2009); Margolis (2010a); Margolis (2010b).

3 Es interesante señalar que hay muchos ámbitos en los que se anuncia "el fin del arte" (especialmente en aquellos influidos por Danto o por Hegel) -o al menos de lo que en Occidente hemos definido como arte en los últimos siglos-, y, sin embargo, la estética de la naturaleza sólo ahora comienza a desarrollarse. Cabe plantearse si, en la estética del futuro, el arte ha de ser reemplazado por la naturaleza o si debe ser desarrollado en paralelo a esta apreciación estética de la naturaleza.

4 Budd (2002), p. 147; Budd (1996), p. 207.

5 Budd (2002), pp. 106 ss.

6 Budd (1996), p. 207.

7 Budd (1996), p. 207.
} 
como él la concibe no sea un tipo específico de experiencia estética de un objeto natural percibido, por ejemplo, como pintoresco o como una obra de arte. En términos de Budd -una vez más-: "en suma, la apreciación estética de la naturaleza, tal como yo entiendo la idea, es idéntica a la apreciación estética no de aquello que es naturaleza, sino de la naturaleza en cuanto naturaleza y no en cuanto arte"8 (en un sentido débil, es decir, no bajo el concepto de un artefacto) o "en virtud de ser natural" (en el sentido fuerte, es decir, bajo el concepto de naturaleza mismo o el concepto de alguna clase particular de fenómeno natural)9. Esta expresión de Budd muestra que reconoce que hay varios sentidos de "naturaleza" y expresa su preferencia por uno de ellos. Esto nos autoriza a afirmar que a partir de su propia visión podemos perfectamente interpretar que la noción de "naturaleza" es ya una "construcción" (si bien no en el sentido idealista de que el "mundo natural" sea construido).

Tal como Budd presenta su propuesta, habría una manera específica de apreciar estéticamente la naturaleza que no puede reducirse o hacerse equivalente a la apreciación "artística" de la naturaleza, aunque, obviamente, esta pueda ser apreciada artísticamente. Pero esta es solo una posibilidad entre muchas (y no es ni la más adecuada ni la más justa) dado que, tal como Budd subraya, "la posibilidad no es lo mismo que la actualidad o la necesidad: el hecho de que sea posible considerar un objeto natural como si fuese una obra de arte no implica que esto sea cómo consideramos o debamos considerar los objetos naturales cuando los experimentamos como bellos" 10 .

La aproximación de Budd sigue la tradición kantiana de concebir el juicio de gusto como desinteresado. Al analizar el pensamiento de Kant respecto a esta cuestión, Budd señala que la belleza de la naturaleza debe entenderse principalmente en términos del desarrollo kantiano de la "belleza libre" (pulchritudo vaga)11, que Kant expone en la Crítica del Juicio §16. Ahí Kant señala que la belleza libre es el objeto de un "juicio puro de gusto"12 sin el concepto de un fin, juzgando solo "según lo que [uno] tiene ante sus sentidos", mientras que la belleza dependiente se juzga "según lo que [uno] tiene en el pensamiento" 13. La belleza dependiente, es, así pues, una belleza "fijada por medio de un concepto de finalidad objetiva y, consiguientemente, tiene que pertenecer al objeto de un juicio de gusto que no sea totalmente puro, sino en parte intelectualizado" 14 .

\footnotetext{
8 Budd (1996), p. 208.

9 Budd (2002), p. 9 ss.

10 Budd (2000), p. 140.

11 Budd (1998b), p. 120.

12 Kant (1995) § 16.

13 Kant (1995) § 16.

14 Kant (1995) § 17.
} 
Siguiendo al pensador de Königsberg, Budd subraya que "un juicio puro de gusto no se basa en el concepto del objeto, en particular en el concepto de la finalidad (o las funciones naturales) del objeto. De ahí que experimentemos un objeto natural bello como si su forma fuese intencional para nuestras capacidades cognitivas, pero sin considerar que eso sea realmente el caso (porque entonces estaríamos experimentándolo como arte, no como naturaleza)"15. En el pensamiento kantiano, no obstante, la categoría de "belleza libre" -objeto del juicio puro de gusto- puede aplicarse también a algunas formas de arte que carecen de cualquier tipo de contenido, lo cual, en cierto modo, supone una dificultad para la restricción que Budd pretende hacer de ese "como si fuese intencional" al espacio de lo natural. Y por otra parte, la categoría de "belleza libre" no puede aplicarse sin más a toda la naturaleza como tal. El mismo Kant advierte que muchas bellezas naturales deben ser consideradas bellezas dependientes, en la medida en que establecen algún tipo de relación "especial" con los seres humanos. ¿Por qué la belleza de un caballo puede considerarse dependiente, pero la de un pájaro exótico es vista como libre? Simplemente porque el caballo forma parte de un mundo de prácticas humanas, mientras que el ave no. Este contraste entre juicio "puro" e "intelectualizado" es lo que, según Gadamer, constituye la diferencia entre belleza libre y dependiente. Dice: “cada vez que 'se pone en juego' el concepto (...) la situación se configura igual que en los ejemplos que aduce Kant para la belleza 'dependiente'. Los ejemplos de Kant -hombre, animal, edificio- designan objetos naturales, tal como aparecen en el mundo dominado por los objetivos humanos (...). En todos estos casos, la determinación teleológica significa una restricción del placer estético"16. Gadamer insiste en que Crítica del Juicio $§ 16$ presenta un árbitro ideal del gusto que juzga según "lo que tiene ante sus sentidos" y no según "lo que tiene en el pensamiento"17. Pero este es el núcleo del asunto, quizá no previsto por Kant y, por eso mismo, no asimilado por Budd, a saber, que toda la belleza se juzga en función de algún tipo de elaboración intelectual más allá de lo que está presente a los sentidos. Y, de este modo, cabe postular que la belleza libre es un recurso teórico que deriva de la inevitable belleza dependiente, la única belleza real posible.

El mismo Kant, cuando aplica su caracterización a la música, por ejemplo, sostiene que a la música pura o no programática, es decir a las fantasías o la música sin texto, que funciona perfectamente sin representación, corresponde la caracterización de belleza libre. Sin embargo, al juzgar de este modo, Kant no parece ser consciente de que este tipo de música está lleno de estructuras, convenciones y reglas estrictas que pertenecen a la "institución" de la música tonal y, en este sentido, o bien la audiencia ignora todas estas determinaciones (lo que parece imposible) o

\footnotetext{
15 Budd (1998a), p. 7.

16 Gadamer (1977), p. 78.

17 Gadamer (1977), p. 79.
} 
caemos de nuevo dentro del ámbito de la belleza dependiente ${ }^{18}$. Lo mismo puede suceder en relación a nuestra apreciación de la naturaleza, en la que el papel de la imaginación está determinado también por algún tipo de "razonamiento" -en términos kantianos-.

En la medida en que la belleza libre prima sobre la belleza dependiente, parece que en el universo kantiano hay que preferir la belleza de la naturaleza (o de una cierta naturaleza) a la belleza del arte (o de un cierto arte), dado que, como afirma D. Townsend, "la naturaleza no muestra ni intencionalidad ni teleología sensible (...). La naturaleza no se preocupa de que alguien la encuentre placentera; todo arte, incluso el arte bello, trata de placer. De ahí que sea precisamente la indiferencia de la naturaleza hacia los intereses humanos y la independencia de los mismos lo que nos permite experimentar un placer verdaderamente desinteresado, pero solo en cuanto a su forma"19. Por esta razón, algunos estudiosos han afirmado que el tratamiento kantiano del arte debería ser visto más como un parergon, un complemento que trata con un conjunto de problemas que el sistema kantiano debería poder resolver, que como una parte integral de su sistema ${ }^{20}$. Pero vemos que el mismo Kant no es claro ni rotundo en esta separación entre arte y naturaleza en función de su atribución de las categorías de belleza libre o dependiente, de intencionalidad o teleología, que también están presentes en ciertas realidades naturales. Es cierto que el sesgo a favor de la belleza natural está presente también en la noción de genio -"la disposición innata (ingenium) mediante la que la naturaleza da la regla al arte"21-, que Kant utiliza para proporcionar una fuente "natural" para el arte, independiente de reglas o conceptos. Por eso Kant se ve obligado a afirmar que el genio es un producto de la naturaleza y no una facultad cognitiva humana.

No obstante, e independientemente de estas observaciones, está claro que Kant concede una enorme importancia a la categoría de "belleza libre". Esto llevó a que muchos autores, sobre todo formalistas, quizá contra el espíritu kantiano, acabasen considerándola como la categoría en la que mejor encaja el arte (y casi exclusivamente el arte), aunque parece que en el desarrollo kantiano la mayoría del arte se explica mejor mediante la categoría de belleza dependiente. Y, ya en esta tradición, algunos autores han llegado a defender que la apreciación artística es el modelo de la apreciación de la naturaleza 22 . Como Budd señala, esta es la postura que defien-

\footnotetext{
18 Kant parece señalar algo de esto en Kant (1995) $\$ 45.2$ y $\S 48.4$, donde se refiere a las intenciones en el arte.

19 Townsend (2003), pp. 87-88.

20 Allison (2001), especialmente la parte 4: "Parerga to the Theory of Taste".

21 Kant (1995), § 46.

22 De otra opinión parece ser, por ejemplo, Richard Wollheim. Véase Wollheim (1972), p. 134, donde afirma que los impresionistas "intentaron enseñarnos a mirar a las pinturas como si estuviéramos mirando a la naturaleza". En el extremo opuesto se encuentra Berys Gaut, quien sostiene que las pro-
} 
de Stephen Davies, en sus Definitions of Art $^{23}$. Podría citarse también a Marcia Muelder Eaton, quien, cuando reflexiona sobre un paisaje, afirma que "tiene valor estético para las personas porque actúan y responden al mismo de maneras semejantes a los modos en que actúan y responden a las obras de arte, es decir, prestan atención a propiedades intrínsecas del paisaje que han sido identificadas como dignas de atención dentro de su cultura", hasta el punto de que muchos paisajes encajan en la definición de arte que propone esta autora, es decir, "son artefactos a cuyas propiedades intrínsecas se presta atención porque son consideradas dignas de percepción y reflexión dentro de una cultura particular y los que prestan atención esperan que esas propiedades causen placer estético"24. Budd considera que esta defensa viene motivada por la influencia de la apreciación del arte sobre la apreciación de la naturaleza, pero eso "no autorizaría una identificación de la apreciación estética de la naturaleza con la apreciación de la naturaleza como si fuese arte"25.

En la defensa de Budd de la apreciación de la naturaleza en cuanto naturaleza, el término clave es "en cuanto [como]". Ya hemos visto cómo desde una consideración estrictamente kantiana y a partir de la distinción entre belleza libre y dependiente no se puede separar la naturaleza del arte, pues hay ejemplares de ambas en las dos categorías, lo que nos da a entender que establecer una separación radical entre arte y naturaleza no es tan fácil como Budd parece suponer, dado que ambas, como veremos, son, finalmente, entidades culturales.

\section{La naturaleza en sí}

La consideración de naturaleza y arte como realidades completamente ajenas entre sí plantea una serie de problemas. En primer lugar, tal consideración supone que podemos distinguir entre naturaleza y lo que no es natural (arte o artefacto) utilizando algo distinto de la naturaleza como una especie de principio opuesto frente al cual podemos identificar la naturaleza qua naturaleza. Budd afirma que "lo que es natural debe ser opuesto no a lo que es hecho por el hombre (otros hombres), sino a lo que es artificial (un producto del artificio humano)" 26 , es decir, determinar qué es natural suponer determinar al mismo tiempo qué es artificial, en tanto que aquello solo se determina por relación a esto. Para Budd, la naturaleza no puede ser considerada como el artefacto de alguien (quizá en oposición a una concepción religiosa o platónica del mundo), puesto que "la apreciación estética de la naturaleza en

piedades estéticas de los objetos de no-arte son "aquellas propiedades que pueden figurar entre las propiedades estéticas de las obras de arte". Gaut (2007), p. 35.

23 Davies (1991), p. 49, citado en Budd (2002), p. 119.

24 Eaton (2000), p. 152. Cursiva mía.

25 Budd (2002), p. 119.

26 Budd (1996), p. 208. 
cuanto naturaleza, para ser fiel a lo que es realmente la naturaleza, debe ser la apreciación estética de la naturaleza no como un objeto intencionalmente producido (y, de este modo, no como arte)"27. Para Budd, cuando apreciamos la naturaleza lo hacemos "con una conciencia diáfana de que la naturaleza no es una creación de la humanidad, sino un producto de fuerzas y procesos naturales" 28 , algo supuestamente dado que queda totalmente separado de cualquier artefacto creado de manera intencional (que parece ser el elemento definitorio del arte, según Budd).

Ahora bien, ¿podemos establecer esta separación radical? Cuando afirmamos que la naturaleza es esto o aquello, habitualmente lo hacemos de un modo apofático. Afirmamos que la naturaleza no es un artefacto, no es una entidad cultural, no es un ente intencional, no es un ente finalista, etc. Estas mismas consideraciones nos hacen tomar conciencia de que, efectivamente, a lo largo de buena parte de la historia de la filosofía, la naturaleza ha sido y aún es pensada como una de estas cosas, o como todas ellas. Afirmar, por ejemplo, que la naturaleza no es teleológica supone insertarse en una determinada concepción de la misma, marcada por un determinado paradigma científico. Igualmente, decimos que no es un artefacto, y al hacerlo dependemos de una visión del mundo que, por ejemplo, excluye cualquier apelación a un principio creador, religioso o no. También decimos que no es cultura. Esto supone una determinada construcción intelectual de la naturaleza, como pone de manifiesto, por ejemplo, Bruno Latour, para quien "la misma noción de cultura es un artefacto creado al poner entre paréntesis la naturaleza. Las culturas -diferentes o universales- no existen más que la Naturaleza. Solo hay naturalezas-culturas"29. Este carácter interpretativo de la naturaleza es algo que está presente casi desde el principio del pensamiento occidental, como puede constatarse, por ejemplo, en la célebre idea de Scoto Eriugena, expuesta ya en el siglo IX, de que toda la realidad -Dios incluido- ha de entenderse en términos de naturaleza (natura), lo opuesto a lo que quiera que signifique el "poner entre paréntesis" de Latour. Mediante su famosa distinción de natura naturans y natura naturata, Scoto no solo defendía que todo es naturaleza, sino que pone sobre el tapete que su misma noción de naturaleza tetraforme es una construcción que incluye absolutamente todo bajo diversas especies. Este carácter constructivo está presente también en infinidad de autores que han tratado de comprender la naturaleza de un modo no inclusivo, sino excluyente: naturaleza frente a espíritu (Hegel), frente a divinidad (Spinoza), frente a arte (Aristóteles), frente a gracia (Tomás de Aquino)... Así, o bien subsumimos todo lo real bajo el concepto de naturaleza o bien definimos esta por medio de una determinada oposición y hacemos que la naturaleza sea una construcción eminentemente cultural, cuyos rasgos variarán según los horizontes que la constituyan.

\footnotetext{
27 Budd (2000), p. 138. Véase también Budd (2002), p. 5.

28 Budd (2002), p. 120.

29 Latour (1993), p. 104, citado en Heyd (2007), p. 127.
} 
Es cierto que, debido a la preeminencia de lo artístico sobre lo natural en la estética identificada con la filosofía del arte, desde el siglo XIX en adelante, la belleza del arte se vuelve la medida de la belleza y eso -según la opinión de R. W. Hepburn- ha dado lugar a un "abandono de la belleza natural" 30 . Esta es una razón poderosa para apreciar la propuesta de Budd de "recuperar" la naturaleza en cuanto naturaleza, un intento que incluso puede ser leído en términos adornianos, si comprendemos la belleza de la naturaleza como algo que está "fuera" del acceso universal de la racionalidad, el mercado, la tecnología, la ciencia, etc. También podríamos -como señala Martin Seel-comprender la naturaleza como un espacio para la contemplación, sin finalidad, como una realidad que invita a sumergirse en ella y a olvidarse de uno mismo, es decir, como un espacio de contemplación que no ha sido configurado o diseñado como tal ${ }^{31}$. Todo esto apunta de nuevo a la idea kantiana de la ausencia de finalidad como constitutiva de la belleza, y seguramente también a la Gelassenheit heideggeraniana del ser, con su probable trasfondo religioso. Para ver la naturaleza como naturaleza debemos despojarnos de todo otro interés y, de modo semejante, de cualquier otra caracterización de la naturaleza que la convertiría en un artefacto. Pero, como se señaló anteriormente, esta manera apofática de aproximarse a la naturaleza supone una determinada interpretación constitutiva de aquello que es naturaleza qua naturaleza, aquello que no se ha de juzgar o comprender en virtud de ninguna otra razón, beneficio o provecho. Y, seguramente, esta lectura de la naturaleza como ese espacio incontaminado y apreciable por sí mismo, fin en sí mismo y objeto de aprecio desinteresado tenga que ver con la sustitución de ciertas categorías religiosas por categorías estéticas. Como afirma Roger Scruton, cuando los pensadores y artistas de la Ilustración se volvieron a la belleza natural, lo hicieron en un intento de llenar el hueco que había dejado la desaparición de Dios en su visión del mundo. Por esa razón, los románticos reemplazaron lo sagrado por la belleza del paisaje como la fuente de sentido32. Para Scruton no es que los románticos encontrasen belleza en la naturaleza, sino que más bien "crearon y transfiguraron la naturaleza mediante la búsqueda de la belleza, que es la búsqueda del hogar" 33 .

Por otra parte, la teoría contemporánea del arte plantea algunos problemas respecto a esta determinación de la naturaleza (entendida como diferente del arte o el artefacto). En primer lugar, podemos referirnos a la cuestión de la indiscernibilidad perceptiva. Uno de los filósofos del arte más importantes del siglo XX, Arthur C. Danto, niega que tenga que haber propiedades visibles que diferencien lo que es arte de lo que no lo es $^{34}$. Lo que hace que algo sea una obra de arte es una "atmósfera

\footnotetext{
30 Hepburn (1966).

31 Seel (1991), p. 38.

32 Scruton (2012), p. 135.

33 Scruton (2012), p. 137.

34 Danto (2002).
} 
de teoría", un conocimiento de la historia del arte que está más allá de lo perceptivo 35 , o, como afirma en otros lugares ${ }^{36}$, una interpretación constitutiva. Pero si no hay propiedades perceptibles que diferencien arte de no-arte (o no tiene que haberlas necesariamente), a fortiori no hay propiedades perceptibles que (necesariamente) distingan lo que es arte de lo que es naturaleza, del mismo modo que no hay diferencias, por ejemplo, entre objetos, actividades y personajes religiosos y profanos, con la única excepción de que, para representarlos, los marcamos como tales (mediante el aura, ciertos espacios, etc...), o los colocamos en un contexto institucional. Por eso, no hay arte sin interpretación, aunque no toda interpretación tenga que interpretar algo como arte y cabe pensar que, análogamente, a falta de estas diferencias perceptivas, es necesaria una determinada interpretación para hablar de naturaleza. Esto parece indicar que no podemos acceder a la naturaleza qua naturaleza, solo a la naturaleza interpretada qua naturaleza, y ciertamente no -como Budd subraya- "como si fuese arte"37, lo cual sería también otro modo de interpretar la naturaleza -distinto, pero semejante en su formalidad- a la interpretación de la naturaleza como naturaleza.

Un ataque más general a la idea de "naturaleza apreciable como naturaleza" procede de la filosofía hegeliana. Para Hegel, lo que define al arte es la belleza y nada más, como queda claro en las primeras líneas de su Estética. Y la belleza -la belleza que a Hegel le interesa- es la belleza del arte. Hegel reconoce que hay también belleza en la naturaleza, pero esta está subordinada a la belleza de las artes, una belleza espiritual que surge de la vida colectiva, lingüística y cultural de una sociedad y del poder creativo de un sujeto o de una serie de sujetos que son parte de una cultura $^{38}$. El arte es esencialmente una manifestación de la libertad humana, que se da precisamente cuando el espíritu humano se apropia de lo natural (sensible) y lo espiritualiza.

Siguiendo la línea de Hegel, Joseph Margolis sostiene que la belleza es un elemento puramente espiritual en el que el espíritu se conoce a sí mismo y se vuelve origen (no hay originales más allá del espíritu que da regla al arte). El origen ya no es la naturaleza, y por eso Margolis critica a Kant de una manera que no se limita a señalar las debilidades que Budd detectaba en el autor de Königsberg en su libro The Aesthetic Appreciation of Nature. Para Margolis, "la contribución de Kant a la estética es simplemente un desastre y tiene que ser completamente desterrada" 39 . Margolis parece poner juntos a Aristóteles y a Kant en una suerte de mundo prehegeliano que es incapaz de comprender la peculiaridad del arte, un mundo domina-

\footnotetext{
35 Danto (1964)

36 Danto (2002), p. 184.

37 Budd (2002), p. 119.

38 Margolis (2009), pp. 24-25.

39 Margolis (2009), p. 14.
} 
do por la doctrina de que la realidad es inmutable y de que lo que es real en el mundo mutable depende incondicionalmente de lo que es inmutable en el mundo real. Esta convicción habría dominado la filosofía desde Parménides a Kant. Por eso llega a afirma que no hay historicidad ni en Aristóteles ni en Kant. Aristóteles, por ejemplo, da por supuesta la invariabilidad de la naturaleza, la interconexión entre las formas válidas de razón y tal invariabilidad, y la capacidad humana para captar las invariabilidades reales de la naturaleza. Algo semejante podría decirse de Kant, cuya "primera Crítica está diseñada para demostrar la adecuación conceptual de su construcción apriorística de la naturaleza" 40 . Hegel es el primero que -frente la identificación aristotélica del arte como un proceso que se da en la naturaleza- distingue un orden de realidad que no puede analizarse en términos naturales (el de la historia y la cultura humana), aunque no pueda existir independientemente de la naturaleza. Queda un espacio que -en términos de Ortega- podría denominarse una "segunda naturaleza"41. Así, podríamos decir que "toda la producción hegeliana (comenzando con la Fenomenología) está diseñada para demostrar que el progresivo autodescubrimiento del Geist (Bildung: la historia mítica de la evolución de la cultura humana) - en la forma de las bellas artes, de la actividad política, la religión o la filosofía- es 'superior a la naturaleza"'42. De hecho, cuando Aristóteles dice que el arte imita la naturaleza, se refiere a que la imita in operando, es decir, que imita el modo de producir las cosas y no la apariencia de las cosas naturales. Esto significa que, mediante el pensamiento teleológico o finalista, el arte impone a la materia una forma que la materia no tiene por naturaleza, como sucede, p.ej., en el caso de una casa. La conclusión que Margolis extrae de esta aproximación es que Aristóteles no tiene una teoría del arte en el sentido cultural, dado que su teoría carece de un concepto desarrollado de cultura ${ }^{43}$. Y algo semejante podría decirse de Kant. Ambos hacen depender el arte de un determinado concepto de naturaleza. Por tanto, el arte no habría roto amarras con respecto a la naturaleza.

La principal idea hegeliana, según Margolis, es, por el contrario, que el arte no puede reducirse a la mímesis en ninguno de los sentidos en los que el término relaciona arte y naturaleza. Esto se debe fundamentalmente a que el arte -como cualquiera de las realidades que informan el mundo cultural- es algo que evoluciona históricamente de modos historizados y emerge sui generis del mundo físico y biológico (pero no puede reducirse a este). Está indisolublemente encarnado en el mundo natural, pero no puede describirse o explicarse por medio de ningún vocabulario que se restrinja al mundo material. Y curiosamente $-\mathrm{y}$ este es el punto clave-, Margolis considera que esto es algo que también se aplica a la naturaleza

\footnotetext{
40 Margolis (2009), p. 33.

41 Margolis (2009), p. 38.

42 Margolis (2009), p. 33.

43 Margolis (2009), p. 45.
} 
misma, de ahí que afirme que "la simple descripción y la explicación de la naturaleza son (ellas mismas) artefactos del mundo cultural" 44 . Según esta caracterización, ver la naturaleza como naturaleza implica una construcción cultural de la naturaleza misma mediante descripciones y explicaciones que la determinen. Así, acabamos invirtiendo los términos: lo que había sido el modelo del arte (la naturaleza) acaba por ser modelado por la cultura. La naturaleza Intencional -en términos de Margolis- de los objetos culturales se extiende también a los objetos naturales.

Es cierto que Budd no establece este contraste entre naturaleza y cultura, sino entre naturaleza y arte (artefacto), pero parece que, se entiendan como se entiendan el arte o el artefacto, no pueden considerarse como algo ajeno al espacio de lo cultural. En último término, como señala Thomas Heyd, "al menos entre las culturas con raíces en Europa (...) los términos 'naturaleza' y 'natural' tienen una significación bastante profunda, en la medida en que designan categorías ontologías fundamentales" 45 , entendiendo la ontología como un modo de clasificar y categorizar la realidad.

\section{Apreciar la naturaleza como naturaleza}

Desde este punto de vista (Hegel-Margolis), ¿qué sentido tendría apreciar la naturaleza como naturaleza (incluso si fuese posible alcanzar esa naturaleza prístina que Budd pretende), si la belleza del arte (incluso la misma contemplación de la naturaleza como arte, a la que Budd se opone) sería de hecho mucho más fructífera?

Ciertamente, Budd no participa de esta corriente. Su kantismo le obliga a sostener, cuando estudia la influencia de los seres humanos en los ambientes naturales, que "la apreciación estética de la naturaleza, para que sea pura, debe abstraer de cualquier diseño impuesto sobre la naturaleza, especialmente de un diseño impuesto para un efecto artístico o estético" 46 . Pero esta misma consideración implica que siempre que haya una suerte de reelaboración artística de la naturaleza tenemos, de algún modo, que descubrir la naturaleza que subyace tras o más allá de esa elaboración o intervención, es decir, "la naturaleza como tal". Sin embargo, no se puede discutir realmente la naturaleza que subyace al "diseño" sin reconocer que ya estamos tratando con un artefacto cultural que cambia históricamente, al igual que lo hace la idea de arte. Y esto es algo que, en algunos momentos, parece reconocer Budd cuando, por ejemplo, en una afirmación que parece recobrar la idea kantiana de la belleza dependiente (ya no libre) dice que "nos deleitamos o nos conmovemos por estados de cosas, procesos, etc. bajo ciertos conceptos o descripciones" $" 47$. No

\footnotetext{
44 Margolis (2009), p. 78

45 Heyd (2007), p. 128.

46 Budd (1996), p. 210.

47 Budd (1996), p. 211.
} 
parece que la naturaleza pueda sustraerse de esta consideración que nos obliga a describir culturalmente algo como naturaleza, y no nos autoriza a afirmar que haya algo así como la naturaleza, existente fuera de nuestra descripción como una suerte de presencia prístina e ininterpretada.

Este modo de comprender la cuestión también parece entrar en conflicto con lo que Budd manifiesta acerca de la indeterminación de la apreciación estética de la naturaleza. Para él "mientras que la categoría bajo la cual cae una obra de arte determina qué modo de abordar la obra y qué propiedades de la misma son relevantes para una evaluación de su valor estético como la obra de arte que es, esto no sucede con los objetos naturales, cuyo abanico de propiedades estéticas o apariencias estéticamente relevantes son típicamente indefinidas y están abiertas de una manera que no es característica de las obras de arte" 48 . Pero si la naturaleza es algo constituido frente a lo que no se considera naturaleza -como lo es el yo en relación con el no-yo-, parece que hay un modo apropiado de apreciar la naturaleza determinado por el modo cultural de constituirla. Y suponer que no es así implica considerar la naturaleza como algo indefinido, abierto, indefinible, quizá. Desde mi punto de vista, en suma, no podemos descubrir la diferencia entre arte y naturaleza en el hecho de que sea un artefacto o no49. Ambos son artefactos culturales. Como sostiene A. Berleant, la naturaleza es un artefacto cultural cuya concepción "ha emergido históricamente y difiere ampliamente de una tradición cultural a otra" 50 . Cualquier categoría por medio de la cual se perciba un objeto natural (sea de índole científica o artística, sea la experiencia del campesino o el caminante, sea el "conocimiento tradicional", el "conocimiento local", el "conocimiento indígena"51 y el conocimiento literario, histórico, antropológico, mitológico, artístico, cinematográfico) viene después de una interpretación fundante.

Para ilustrar mejor este punto, ofrezco un ejemplo que hace referencia a una exposición sobre Rembrandt, organizada por el Metropolitan Museum of Art de Nueva York en 200752, en la que, para mostrar el contexto histórico del artista, el comisario ubicó sus obras junto a las de pintores contemporáneos (Vermeer, Frans Hals, etc.). Poco después, en el mismo museo, se instaló el famoso tiburón preservado en formaldehído de Damien Hirst que lleva el impactante título (probablemente para asegurar su carácter artístico) de "The Physical Impossibility of Death in the Mind of Someone Living". La cronista del New York Times, Roberta Smith, afirmaba en este periódico: "si se trasladase al American Museum of Natural History, al

\footnotetext{
48 Budd (2006), p. 268

49 Aquí afrontamos el problema de la "artefactualidad misma", a la que George Dickie dedica algunas páginas en Dickie (2005), cap. 3.

50 Berleant (1992), p. 380 [en la reimpresión].

51 Heyd (2007), pp. 33 ss. La crítica de Heyd a Carlson está en las pp. 79-92.

52 Smith (2013).
} 
otro lado de Central Park, puede que uno no se parase a mirar dos veces". Miramos dos veces porque es una obra de arte y no una pieza de historia natural. Para subrayar su estatus artístico, el comisario de la exposición, Gary Tinterow, colgó en la galería tres pinturas pertenecientes a la colección del museo cuyos temas estaban relacionados con el mundo de los tiburones, una de las cuales había sido pintada por Bacon. De este modo establecía una narrativa artística. Pero perfectamente, como señalaba Roberta Smith, podríamos haber elaborado una narrativa diferente colocándola en el Museo de Historia Natural, con lo que se hubiese convertido, sin más, en un "fragmento de naturaleza". Parece, una vez más, que la diferencia entre arte y naturaleza es la interpretación previa, no la materialidad del objeto.

Para concluir: ¿qué significa, entonces, apreciar la naturaleza qua naturaleza -desde un punto de vista hegeliano-margoliano- teniendo presente que la misma comprensión de la naturaleza -y su apreciación- es necesariamente Intencional/cultural? ¿Qué significa realmente "apreciar la Naturaleza como lo que realmente es"?53 ¿Qué es realmente apreciar la naturaleza? Como se ha venido insistiendo, Budd afirma que "los objetos naturales no deberían ser apreciados estéticamente bajo concepto alguno en absoluto (excepto aquellos de la naturaleza misma) ${ }^{54}$, con lo que, como se ha dicho, puede estar tratando de recobrar la intuición de Kant relativa a la belleza libre. Pero, ¿podemos tener un "concepto de naturaleza"? Desde luego no en el sentido altamente técnico que "concepto" tiene en la Crítica del Juicio de Kant. Al final, apreciamos algo que interpretamos como natural y nos deleitamos en ello, de modo análogo a cuando decimos, por ejemplo, que debemos vivir según la naturaleza como criterio ético. También en este caso establecemos (e interpretamos) la naturaleza como una fuente de valores y la convertimos, así, en un referente ético.

\section{Referencias bibliográficas}

Allison, H. E. (2001): Kant's theory of taste, Cambridge: Cambridge University Press.

Berleant, A. (1992): "The aesthetics of art and nature", en A. Berleant, The aesthetics of environment, Philadelphia, Temple University Press, pp. 160-175, reimpreso en J. O. Young (ed.), Aesthetics. Critical concepts in philosophy, London \& New York, Routledge, 2005, vol III, pp. 375-387.

BudD, M. (1996): "The aesthetic appreciation of nature", British Journal of Aesthetics, 36, pp. 207-222.

\footnotetext{
53 Budd (2000), p. 142.

54 Budd (2000), p. 142.
} 
BudD, M. (1998a): "Delight in the natural world: Kant on the aesthetic appreciation of nature. Part I: natural beauty", British Journal of Aesthetics, 38, pp. 2-18.

BudD, M. (1998b): "Delight in the natural world: Kant on the aesthetic appreciation of nature. Part II: natural beauty and morality", British Journal of Aesthetics, 38, pp. 117-126.

Budd, M. (2000): "The aesthetics of nature", Proceedings of the Aristotelian Society, 100, pp. 137-157.

BudD, M. (2002): The aesthetic appreciation of nature, Oxford-New York, Oxford University Press.

BudD, M. (2006): "Objectivity and the aesthetic value of nature: reply to Parsons", British Journal of Aesthetics, 46, pp. 267-273.

CARLSON, A. (1979): "Appreciation and the natural environment", The Journal of Aesthetics and Art Criticism, 37, pp. 267-276, reimpreso en James O. Young (ed.), Aesthetics. Critical concepts in philosophy, London \& New York, Routledge, 2005, vol. III, pp. 362-374.

Crawford, D. W. (1974): Kant's aesthetic theory, Madison, WI: University of Wisconsin Press.

Danto, A. C. (1964): “The Artworld”, The Journal of Philosophy 61, pp. 571-584.

DAnTo, A. C. (2002): La transfiguración del lugar común, Barcelona, Paidós.

DAviEs, S. (1991): Definitions of Art, Ithaca and London, Cornell University Press.

Dickie, G. (2005): El círculo del arte, Barcelona, Paidós.

EAton M. M. (2000): “A sustainable definition of 'Art", en N. Carroll (ed.), Theories of Art Today, Madison, Wisconsin, The University of Wisconsin Press. GADAMER, H.G. (1977): Verdad y método, Salamanca, Sígueme.

Gaut, B. (2007): Art, emotion and ethics, Oxford, Oxford University Press.

HePBuRn, R. W. (1996): "Contemporary aesthetics and the neglect of natural beauty”, en B. Williams and A. Montefiore (eds.), British analytical philosophy, London, Routledge and Kegan Paul, pp., 285-310, reimpreso en J. O. Young (ed.), Aesthetics. Critical concepts in philosophy, London \& New York, Routledge, 2005, vol. III, pp. 341-361.

HeYD, T. (2007): Encountering nature, Aldershot, Ashgate.

KANT, I. (1995): Crítica del Juicio, Madrid, Espasa Calpe.

KANT, I. (2008): Observaciones acerca del sentimiento de lo bello y de lo sublime, Madrid, Alianza.

LATOUR, B. (1993): We have never been modern, Cambridge, MA, Harvard University Press.

MARGOLIS J. (2004): "Placing Artworks-Placing Ourselves", Journal of Chinese Philosophy, 31, pp. 1-16.

Margolis J. (2009): On Aesthetics. An unforgiving introduction, Belmont, CA, Wadsworth. 
MARGOLIS J. (2010a): The cultural space of the arts and the infelicities of reductionism, New York, Columbia University Press.

Margolis J. (2010b): What, after all, is a work of art?, Philadelphia, Penn State Press.

Parsons, G. (2007): “The aesthetics of nature”, Philosophy Compass 2, pp. 358372.

Pogrebin, R. (2010): "Museum sells pieces of its past, reviving a debate", The New York Times, 12-5-2010. <http://www.nytimes.com/2010/12/06/arts/design/ 06sales.html?nl=today $>$ consultado el 15 de octubre de 2013.

SCRuton, R. (2012): The face of God, London-New York, Continuum.

SeEl, M. (1991): Eine Ästhetik der Natur, Frankfurt a.M., Suhrkamp.

Sмith, R. (2007): "Just when you thought it was safe", The New York Times, 10-162007. <http://www.nytimes.com/2007/10/16/arts/design/16muse.html?adxnnl= 1\&adxnnlx=1378997332-zrkN8I0qV6pKBOD0LzpE9w $>$ consultado el 15 de octubre de 2013.

SonTAG, S. (2007): "La estética del silencio", en Estilos radicales, Barcelona, DeBolsillo.

Townsend, D. (2003): "Art and the aesthetic: Hume, Kant, and the essence of art", en S. Davies and A. Ch. Sukla (eds.), Art and essence, Westport, Conn-London, Prager.

Wollheim, R. (1972): El arte y sus objetos, Barcelona, Seix Barral.

Sixto J. Castro

Departamento de Filosofía

Universidad de Valladolid

sixto@fyl.uva.es 